Natividad A. Almazan - Aguilar, MD, M.Sc. ${ }^{1,2}$

'Department of Otolaryngology Head and Neck Surgery Manila Central University

2Department of Otolaryngology Head and Neck Surgery St. Luke's Medical Center
Correspondence: Natividad A. Almazan - Aguilar, MD, MSC Department of Otolaryngology Head and Neck Surgery

St. Luke's Medical Center

279 E. Rodríguez Ave., Quezon City 1102

Philippines

Telefax (632) 723-1016

Reprints will not be available from the author.

Funding for this study was supported by a grant from the Philippine Council for Health Research Development (PCHRD). The author signed a disclosure that while she had no proprietary or financial interest with any organization that may have a direct interest in the subject matter of this manuscript during the course of research, she has performed unrelated research funded by, and is currently a speaker for Glaxo Smith-Kline (Consumer Division). She is also a speaker for UCB Pharma and United American Pharmaceuticals at present.

This manuscript was adapted from the original thesis submitted to the University of the Philippines Manila in partial fulfillment of the requirements for the degree Master of Science in Clinical Epidemiology, 2004.

\title{
Intranasal Corticosteroids for the Medical Management of Nasal Polyps in Adults: a Meta-Analysis
}

\begin{abstract}
Background: This systematic review aims to strengthen evidence of beneficial effects of intranasal corticosteroids on the medical treatment of adults diagnosed with nasal polyps.
\end{abstract}

Objective: (1) To determine efficacy of short-term (2-4 weeks) and long-term (4-12 weeks and > 12 weeks) use of intranasal corticosteroids for reduction of polyp size and rhinitis symptoms. (2) To determine difference in efficacy of a 400 and $800 \mu \mathrm{g}$ dose. (3) To determine adverse effects of intranasal steroids.

Study Design and Selection Criteria: Meta-analysis of randomized controlled trials on intranasal steroids for nasal polyps. Patient-oriented outcomes were reduction of polyp size and overall reduction of rhinitis symptoms.

Search strategy: Comprehensive search of Cochrane's Controlled Trials Registry (CCTR) Issue 2, 2003, Medline 1966 - 2002, Embase 1974 - 2002, bibliographic review, requests for information from authors and pharmaceutical companies.

Data collection and analysis: Sixteen studies were evaluated for inclusion, and trial quality, validity assessment, and completion of data extraction were done. Ordinal data on rhinitis and polyp scores for each study were pooled to generate relative risks. Homogeneity was assessed using approximate chi-square tests. Preset $p$ value of $<0.10$ was deemed significant for heterogeneity. Data was analyzed using Revman 4.1 (Update Software, Oxford). Sensitivity analysis was done for outcomes with significant heterogeneity.

Results and Conclusion: Fourteen studies found significant benefit for the use of intranasal steroids in reduction of polyp size with $2-4$ weeks treatment ( $R R=3.00 ; 95 \% \mathrm{Cl}: 2.39,3.77$ ).

Overall rhinitis symptoms decreased significantly ( $\mathrm{RR}=1.64 ; 95 \% \mathrm{Cl}: 1.25,2.14)$ with $4-12$ weeks treatment, with a tendency for reduction of rhinitis symptoms ( $\mathrm{RR}=1.41 ; 95 \% \mathrm{Cl}: 1.05,1.91$ ) with more than 12 weeks treatment. Throat irritation was significantly increased $(R R=2.06 ; 95 \%$ $\mathrm{Cl} 1.31,3.25)$. There was no difference in overall rhinitis symptoms ( $\mathrm{RR}=0.91 ; 95 \% \mathrm{Cl}: 0.77,1.07)$ with $400 \mu \mathrm{g}$ and $800 \mu \mathrm{g}$ doses.

Keywords: polyp, nose, steroids, intranasal steroids, glucocorticosteroid

The foremost objective in the treatment of nasal polyps is their disappearance, if not reduction of polyp size'. Although surgical therapy continues to play an important role in the 


\section{ORIGINAL ARTICLES}

management of nasal polyps ${ }^{2}$, there is always the risk of complications and the recurrence rate is about 40 percent $^{3}$.

In clinical practice, the main concern of patients with nasal polyps is reduction of overall rhinitis symptoms that include nasal obstruction, nasal discharge, sneezing, itchiness and anosmia. The goal of treatment of nasal polyps focuses on control of these symptoms and removal of the polyps without causing complications that will be detrimental to health.

Over the past decade, there have been improvements in the medical treatment of nasal polyps. A search made by the Cochrane ENT Registry Group revealed that 24 of the 45 Randomized Controlled Trials (RCTs) showed beneficial results in favor of intranasal corticosteroids.

Topical nasal steroids such as budesonide, betamethasone and fluticasone have been known since the 1960's to cause some polyp shrinkage ${ }^{4}$. Glucocorticoids display a favorable therapeutic profile directly preventing polyp formation and growth and reducing local pathology and inflammatory exudates together with bacterial colonization. Randomized Controlled Trials (RCTs) on intranasal steroids for nasal polyps looked at a variety of clinical outcomes. Studies looking at the same outcome often used different measurement scales. It would be helpful to the clinician if results could be compared across studies.

Because of the growing demand for medical treatment of nasal polyps, intranasal steroids will continue to be a cornerstone of polyp management. It is the aim of this review to quantify the effect of intranasal corticosteroids in terms of improvement of nasal symptoms and reduction in polyp size. A systematic review on RCTs was conducted to determine the favorable dose and duration as well as the occurrence of adverse effects.

Objectives: This study aimed to determine the efficacy and safety of intranasal corticosteroid therapy and sought to achieve the following specific objectives:

1. To compare short-term (2-4 weeks) intranasal corticosteroid therapy with placebo in the improvement of clinical outcomes, as measured by

a. reduction of polyp size;

b. reduction of overall rhinitis symptoms (a combination of

nasal obstruction, nasal discharge, itchiness and sneezing); and c. peak nasal inspiratory flow (PNIF)

2. To compare long-term (4-12 and $>12$ weeks) intranasal corticosteroid therapy with placebo in the improvement of the clinical outcomes stated above.

3. To compare the frequency of adverse effects between intranasal steroids and placebo.

4. To compare $400 \mu \mathrm{g}$ versus $800 \mu \mathrm{g}$ intranasal corticosteroids in the improvement of clinical outcomes stated above.

\section{METHODS}

Identification of Trials: The electronic bibliographic database MEDLINE/Pubmed was searched for all articles in English using the standardized subject terms "nasal polyps," "intranasal steroids" or "steroids, fluorinated" and "randomized controlled trial" (Publication Type) from years 1970 to 2002 .
Communication with the UK Cochrane Center ENT Research Group was done for further comprehensive search of articles especially for non-English titles. The ENT Specialist Registry Group searched the following: (1) Cochrane Central Register of Controlled Trials (CENTRAL), (2) Medline, (3) EMBASE (the Reed-Elsevier Excerpta Medica database) (4) Cumulative Index to Nursing and Allied Health Professionals (CINAHL), (5) Allied and Complementary Medicine (AMED), (6) Meta Register of Clinical Trials (mRCT), and (7) Latin American Caribbean Health Sciences Literature (LILACS). The abstracts retrieved by the Cochrane Group were not limited to RCTs. The bibliographies of candidate RCTs were further reviewed to identify more studies. Full text articles were requested from drug companies and friends from the United States.

Study Selection: Three reviewers independently read the methods section of the candidate articles for meta-analysis and applied the stated criteria for inclusion in this review. Disagreements were resolved by discussion until a consensus was reached. The following criteria were used to select the studies for meta-analysis:

Study design: Restricted to randomized, parallel, double blind, placebo-controlled trials on intranasal glucocorticosteroids for nasal polyps.

Study population: RCTs on adults clinically diagnosed to have nasal polyps objectively on anterior rhinoscopy and nasal endoscopy in hospital outpatient clinics or specialty private clinics. Individual RCTs were excluded if any of the following patient characteristics were present: previous use of steroids, sinusitis, upper respiratory tract infection, presence of structural abnormality of the nose and significant co-morbidities.

Types of intervention: All types of intranasal corticosteroids (e.g. beclomethasone dipropionate, budesonide, and fluticasone propionate) compared to placebo were included. These variables were included; (1) solvent delivery (aqueous or powder); (2) manner of administration (spray, turbohaler); (3) duration of use -- short-term (2-4 weeks) and long-term (4-12 weeks and > 12 weeks); and (4) dosage (400 $\mu \mathrm{g}$, and $800 \mu \mathrm{g})$. The placebo made use of the same method of delivery (isotonic aqueous solution or non-medicated powder), manner of administration, and kind of container.

Outcome measures: (1) reduction in size of polyp reported as polyp size score; (2) reduction in rhinitis symptoms; and (3) adverse effects such as epistaxis, nasal itchiness and throat irritation. The effects of duration ( 2 to 4 weeks, 4 to 12 weeks, and > 12 weeks) and dose (400 $\mu \mathrm{g}, 800 \mu \mathrm{g}$ ) of treatment on these outcomes were also studied. PNIF, an objective measure of nasal obstruction, was also included.

Quality Assessment: Three reviewers independently assessed the methodological quality of each candidate RCT using the quality assessment tool developed by the Philippine Cardiovascular Research Group (Appendix A). ${ }^{5}$ This assessment instrument classified study quality according to selection, performance, detection, and exclusion biases, using $A, B$, or $C$ ratings where $A$ represents the highest score, $B$ the middle score and $C$ the poorest quality score. Factors checked to determine which bias was present included: allocation concealment for selection bias, blinding of patients for performance bias, dropouts for 
ORIGINAL ARTICLES

\begin{tabular}{|c|c|c|c|c|c|c|c|c|}
\hline \multirow[b]{2}{*}{ Study } & \multirow{2}{*}{$\begin{array}{c}\text { No. of } \\
\text { patients }\end{array}$} & \multirow{2}{*}{$\begin{array}{c}\text { Age } \\
\text { range (yrs) }\end{array}$} & \multirow{2}{*}{$\begin{array}{l}\text { Duration of } \\
\text { treatment }\end{array}$} & \multirow[b]{2}{*}{ Drug/ dose $(\mu g)$} & \multicolumn{3}{|c|}{ Outcome } & \multirow[b]{2}{*}{$\begin{array}{l}\text { Quality } \\
\text { Assessment } \\
\text { Score }\end{array}$} \\
\hline & & & & & Polyp size & Rhinitis symptoms & Adverse effects & \\
\hline Holmberg, 1997 & 55 & $21-71$ & 2 to 4 weeks & $\begin{array}{l}\text { fluticasone } p \text { aqueous } 400 \\
\text { BDP aqueous } 400\end{array}$ & Y & Y & Y & B \\
\hline Lund, ${ }^{13} 1998$ & 29 & $22-72$ & $\begin{array}{l}2 \text { to } 4 \text { weeks } \\
4 \text { to } 12 \text { weeks }\end{array}$ & $\begin{array}{l}\text { fluticasone d aqueous } 400 \\
\text { BDP aqueous } 400\end{array}$ & Y & Y & Y & B \\
\hline Tos, $_{1}^{14} 1998$ & 138 & $20-82$ & $\begin{array}{l}2 \text { to } 4 \text { weeks } \\
4 \text { to } 12 \text { weeks }\end{array}$ & $\begin{array}{l}\text { budesonide aqueous } 256 \\
\text { budesonide powder } 240\end{array}$ & Y & Y & Y & B \\
\hline Lildholdt, ${ }_{1}^{15} 1997$ & 124 & $20-81$ & 2 to 4 weeks & $\begin{array}{l}\text { budesonide powder } 400 \\
\text { budesonide powder } 800\end{array}$ & Y & Y & Y & B \\
\hline Karlsson, ${ }^{16} 1982$ & 40 & $23-79$ & 2 to 4 weeks & BDP aqueous 400 & Y & N & N & B \\
\hline Mygind, ${ }^{17} 1975$ & 35 & $19-78$ & 2 to 4 weeks & BDP aqueous 400 & $Y$ & Y & N & B \\
\hline Dingsor, ${ }^{11} 1985$ & 41 & $18-73$ & $\begin{array}{l}2 \text { to } 4 \text { weeks } \\
4 \text { to } 12 \text { weeks }\end{array}$ & Flunisolide aqueous 200 & Y & N & $\mathrm{N}$ & B \\
\hline Virolainen, ${ }^{18} 1980$ & 40 & $28-72$ & $\begin{array}{l}2 \text { to } 4 \text { weeks } \\
\geq 12 \text { weeks }\end{array}$ & BDP aqueous 400 & Y & Y & Y & B \\
\hline Chalton, ${ }^{19} 1985$ & 30 & $14-66$ & 2 to 4 weeks & betamethasone aqueous 200 & Y & N & N & B \\
\hline Holopainen, ${ }^{20} 1982$ & 19 & $18-62$ & 2 to 4 weeks & BDP aqueous 400 & Y & Y & $\mathrm{N}$ & $C$ \\
\hline Toft, $_{,}^{21} 1982$ & 42 & $23-78$ & 2 to 4 weeks & $\begin{array}{l}\text { BDP powder } 400 \\
\text { BDP aqueous } 400\end{array}$ & N & N & Y & B \\
\hline Lildholdt, 1995 & 120 & & 2 to 4 weeks & $\begin{array}{l}\text { budesonide aqueous } 400 \\
\text { budesonide aqueous } 800\end{array}$ & Y & Y & $\mathrm{N}$ & $C$ \\
\hline Ruhno, ${ }^{22} 1990$ & 36 & $20-68$ & 2 to 4 weeks & budesonide aqueous 800 & N & Y & Y & B \\
\hline Jankowski, ${ }^{23} 2001$ & 161 & $18-76$ & 2 to 4 weeks & $\begin{array}{l}\text { budesonide } 128 \text { BID } \\
\text { budesonide } 2560 D \\
\text { budesonide } 1280 D \\
\text { (all aqueous) }\end{array}$ & $Y$ & Y & Y & B \\
\hline Pentilla, ${ }^{10} 2000$ & 142 & $22-83$ & $\begin{array}{l}2 \text { to } 4 \text { weeks } \\
4 \text { to } 12 \text { weeks } \\
\geq 12 \text { weeks }\end{array}$ & $\begin{array}{l}\text { fluticasone } p \text { aqueous } 400 \\
\text { fluticasone } p \text { aqueous } 800\end{array}$ & Y & Y & Y & C \\
\hline Johansen, ${ }_{1}^{6} 1993$ & 91 & $18-78$ & 2 to 4 weeks & budesonide aqueous 400 & $Y$ & $Y$ & $\mathrm{~N}$ & B \\
\hline
\end{tabular}

exclusion bias, and blinding of examiners for detection bias. The lowest score in any of the four bias groups corresponded to the total score of the assessment. Discrepancies in the ratings of the three reviewers were resolved by the rule of majority.

Data Extraction: Data for the specified outcomes were extracted independently by three reviewers based on reported summary statistics (means, SD, proportions). Data measured at several points were grouped into 2-4 weeks, 4-12 weeks and $>12$ weeks. All data were entered into Revman 4.1 (Update Software, Oxford).

All studies reported polyp size using Johansen's ${ }^{6} 4$-scale classification: 0 , no polyps; 1 , mild; 2, moderate; and 3, severe. For several rhinitis symptoms, the RCTs utilized 3 different classification schemes, as follows:

(1) Scale of 0 - 3: 0 - None; 1 - Mild; 2 - Moderate; 3 - Severe

(2) Scale of 0 - 5: 0 - Symptoms aggravated; 1-No control of symptoms; 2-Minor control of symptoms; 3 - Substantial control of symptoms; 4 - Total control of symptoms

(3) Johansen scale of 1-4: 1-absent; 2-a few episodes; 3-many episodes; 4-continuous

These ordinal scores were dichotomized into positive or negative reduction. Positive reduction was defined as any one scale reduction towards benefit or difference before and after treatment. Negative reduction was defined as no reduction or any change in scale towards harm before and after treatment. Disagreements in data extraction were resolved by consensus.

\section{Data Analysis}

Study Selection: Kappa statistic ${ }^{7}$ was used to assess the interobserver agreement for study selection. A value of $\mathrm{K} \leq 1.0$ was considered agreement beyond chance.

Meta -analysis proper: Where dichotomous outcome measures could be assessed, the treatment effect was calculated as the difference in relative risk before and after treatment. All analyses were performed according to the intention-to-treat method, i.e. including all randomized patients. Patients with results of no reduction in polyp size or overall rhinitis symptoms were considered as failures. The software package 
(Revman 4.1) provided by the Cochrane Collaboration ${ }^{8}$ was used. The pooled effect sizes and their corresponding $95 \%$ confidence intervals $(\mathrm{Cl})$ were reported for each outcome, using the fixed effects model.

The studies were grouped according to the size of the polyp using the classification of Mackay. ${ }^{9}$ Small polyps were defined as those with a polyp scale score of one and big polyps as those with a polyp scale score of two and three. Duration and dose of intranasal steroid use were based on previous studies. ${ }^{10,5,11}$ Differentiation between the usual dose of $400 \mu \mathrm{g}$ and a high dose of $800 \mu \mathrm{g}$ was done because one of the outcome measures was reduction in polyp size. Studies utilizing subjects with smaller polyps may show better results with intranasal steroids.

Test of heterogeneity among studies: Homogeneity among studies was tested by the chi-square test, where a $p<0.10$ was considered statistically significant. Statistical heterogeneity ${ }^{7}$ (differences in the reported effects), methodological heterogeneity (differences in study design) and clinical heterogeneity (differences between studies in characteristics of the participants, interventions or outcome measures) ${ }^{8}$ were also explored.

\section{RESULTS}

Description of the Studies: The 27 studies were further reviewed by three otolaryngologists/clinical epidemiologists for inclusion or exclusion. Only 16 articles were finally included (Table 1). The kappa coefficient ${ }^{7}$ between the two raters was 0.85 (standard error $=0.19$ ), indicating substantial agreement.

The studies totalled 1,170 patients (mean age 49 years, range 14 to 83 years) with bilateral nasal polyps, who had one or more previous polypectomies that complied with the inclusion criteria, and from which we were able to obtain sufficient data either directly or after transforming continuous data to dichotomous data based on our preset definition of outcome measures or after corresponding with the first author or the sponsoring drug companies.

All 16 studies (Table 1) included were done in a multi-center outpatient clinic or specialty private practice (in Europe and Canada where all the studies occurred, these two settings are fairly equivalent and the seven countries included Denmark, Sweden, Canada, United Kingdom, Finland, Norway, France). The patients in the studies reported a history of nasal obstruction, sneezing, nasal discharge and occasionally anosmia. Diagnosis of nasal polyps was made by nasal examination with anterior rhinoscopy and nasal endoscopy, which showed polyps in the nasal cavity. The polyps were then measured using a defined scoring system. ${ }^{6}$

All 16 studies compared intranasal steroids with placebo. Two studies ${ }^{14,21}$ showed the effect of different formulations (aqueous versus nonaqueous), three studies, 1,10,22 the effect of different doses (400 $\mu \mathrm{g}$ versus $800 \mu \mathrm{g}$ ), and two studies, ${ }^{12,13}$ the effect of different types of steroids.

\section{Effect of Short-term Intranasal Corticosteroids Reduction in polyp size}

Fourteen ${ }^{1,6,10-20,23}$ out of 16 included studies compared intranasal steroids to placebo for 2 to 4 weeks duration. Intranasal steroids showed a clear effect over placebo on polyp size reduction $(R R=3.00$, $95 \% \mathrm{Cl}: 2.39,3.77)$. There was no significant heterogeneity among the trials $\left(X^{2}=19.72, p=0.10\right.$, Figure 1$)$.

\section{Reduction in rhinitis symptoms score}

Of the 16 RCTs, 12 reported the effect of steroids administered from 2 to 4 weeks on the overall rhinitis symptoms score. There was significant heterogeneity in the risk of reduction of symptoms $\left(X^{2}=44.08, p<0.01\right)$. The pooled risk of rhinitis symptom reduction was $\mathrm{RR}=2.56(95 \% \mathrm{Cl}$ : 2.13, 3.08)

PNIF

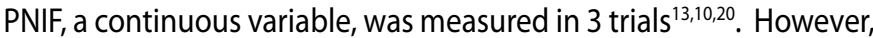
the trials did not report standard deviations or absolute values of test-statistics and $p$-values, which are required for pooling studies. The mean difference of PNIF between the steroid and placebo groups could not be calculated without this information.

\section{Effect of Long-term Use (4-12 weeks and >12 weeks) of Intranasal Corticosteroids \\ Reduction of polyp size, 4 to 12 weeks}

Four $10,11,13,14$, out of 16 studies showed the effect of intranasal steroids given for 4 to 12 weeks on the reduction of polyp size when combined. There was significant reduction in polyp size that favored steroids over placebo ( $R R=2.89 ; 95 \% \mathrm{Cl}: 1.99,4.18)$. However, a significant heterogeneity across studies was noted $\left(X^{2}=11.14, p=0.01\right)$.

\section{Reduction of overall rhinitis symptoms, 4-12 weeks}

The same four studies ${ }^{10,11,13,14}$ reported the comparison of intranasal steroids and placebo in terms of the effect on rhinitis symptoms after 4-12 weeks. Fixed effect analysis demonstrated that intranasal corticosteroids have a beneficial effect over placebo on reduction in rhinitis symptoms ( $\mathrm{RR}=1.64 ; 95 \% \mathrm{Cl}: 1.25,2.14)$. There was no significant heterogeneity $\left(X^{2}=0.73, p=0.87\right.$, Figure 2$)$.

\section{Reduction of polyp size, $>12$ weeks}

No study reported effects of treatment of $>12$ weeks on polyp size.

\section{Reduction of overall rhinitis symptoms, $>12$ weeks}

Two studies ${ }^{10,18}$, (total $n=182$ ) were pooled and showed significant benefit with intranasal steroids versus placebo in reducing rhinitis symptoms when given $>12$ weeks (RR $=1.41 ; 95 \% \mathrm{Cl}: 1.05,1.91)$. Tests for heterogeneity showed the studies were homogeneous and comparable $\left(X^{2}=0.81, p=0.44\right)$. However, one study ${ }^{19}$ had a lower $\mathrm{Cl}$ value of $<1$ showing no statistically significant effect when analyzed singly (Fig 3).

In summary, the use of intranasal steroids for a longer period of 4-12 weeks and $>12$ weeks significantly reduced the overall rhinitis symptoms. Studies on polyp size reduction for 4-12 weeks were heterogeneous.

\section{Medication Side Effects of Intranasal Steroids}

The three most common side effects reported in the 16 randomized controlled trials included were found to be epistaxis or bloody discharge, nasal itchiness and throat irritation.

Epistaxis: Seven studies reported epistaxis as an adverse effect of intranasal steroids. The risk of epistaxis with the use of intranasal 
ORIGINAL ARTICLES

\section{Fig 1. Reduction of Polyp Size Score, 2 to 4 weeks}

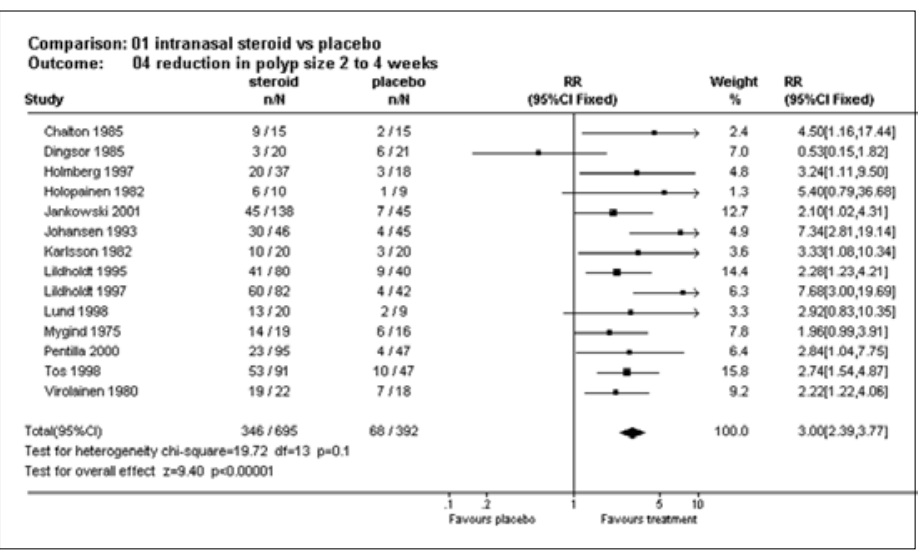

\section{Fig 2. Reduction of Rhinitis Symptoms, 4 to 12 weeks}

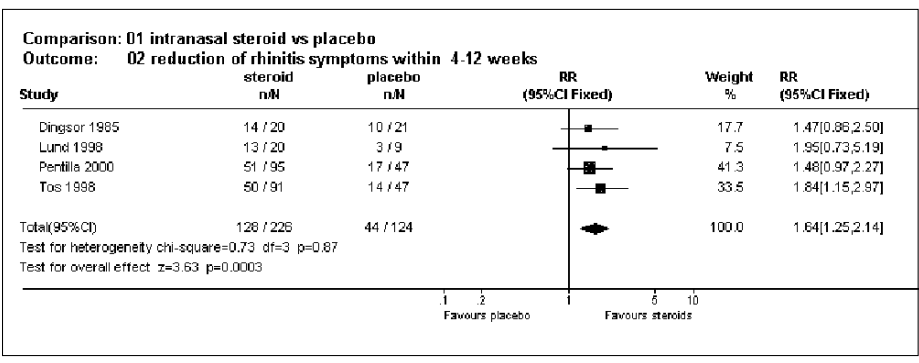

Fig 3. Reduction of Rhinitis Symptoms, morethan 12 weeks

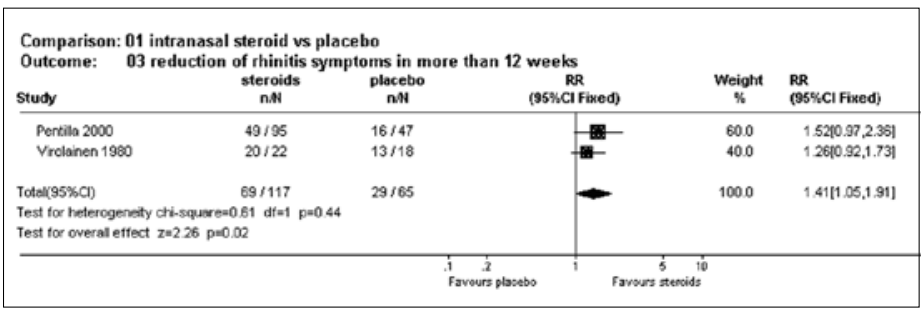

Fig 4. Nasal Itchiness

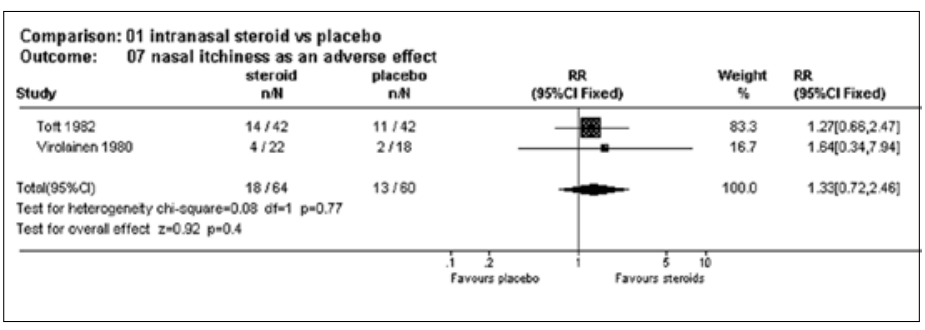

Fig 5. Throat Irritation

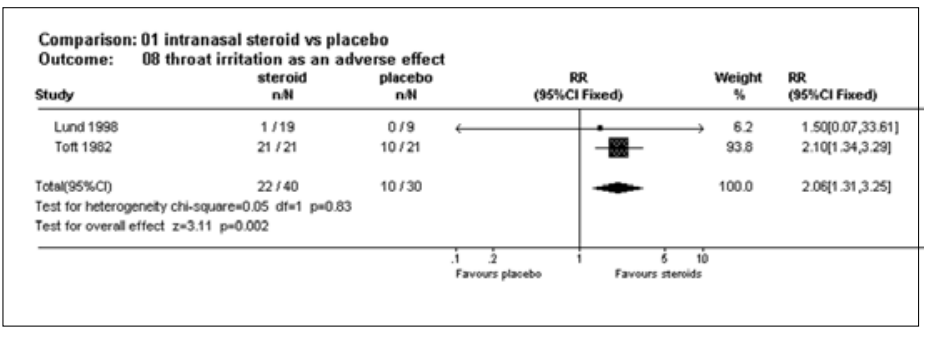

Fig 6. Reduction of Rhinitis Symptoms, $400 \mu \mathrm{g} v .800 \mu \mathrm{g}$

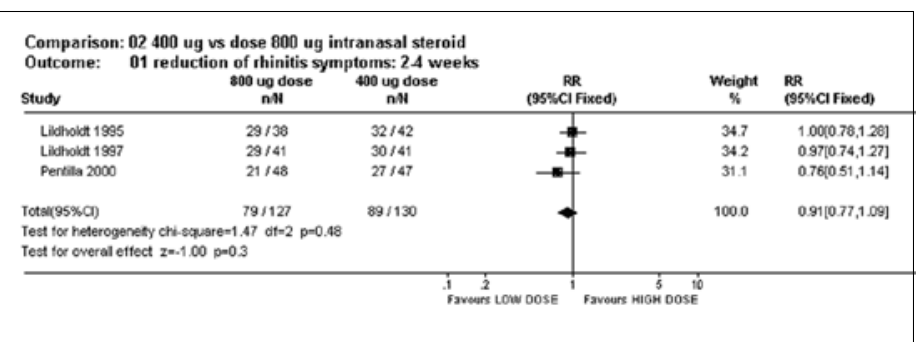

steroids compared to placebo was statistically significant $(\mathrm{RR}=1.95$; $95 \% \mathrm{Cl}: 1.37,2.77)$. However, this finding is inconclusive because it was noted when pooling the studies heterogeneity $\left(X^{2}=18.57, p\right.$ $<0.006$ )

Nasal itchiness: When the two studies ${ }^{18,21}$ that reported nasal itchiness as an adverse effect were combined $\left(X^{2}=0.08, p=0.77\right)$, the results showed that the risk of nasal itchiness did not significantly differ between intranasal steroids and placebo $(\mathrm{RR}=1.33 ; 95 \% \mathrm{Cl}$ : $0.72,2.45$, Fig 4).

Throat Irritation: On the other hand, the risk of throat irritation was greater in patients treated with intranasal corticosteroids than those in placebo ( $\mathrm{RR}=2.06 ; 95 \% \mathrm{Cl}: 1.31,3.25)$. The effect size of the two studies ${ }^{13,21}$ were noted to be homogeneous $\left(X^{2}=0.05, p=\right.$ 0.83, Fig 5).

In summary, the side effect which was significantly greater with the use of intranasal steroids was throat irritation. Nasal itchiness was not significantly different from intranasal steroids as compared to placebo.

Comparison of $400 \mu \mathrm{g}$ vs. $800 \mu \mathrm{g}$ Dose of Intranasal Steroids: The two different types of intranasal steroids, budesonide and fluticasone were found to have no difference in drug bioavailability, with terminal plasma half life of three hours. The dose delivered per nasal spray actuation was $64 \mu \mathrm{g} / \mathrm{actuation}$ for budesonide and 50 $\mu \mathrm{g} /$ actuation for fluticasone. The dose of intranasal steroids given is determined by the number of sprays delivered into the nasal cavity and the average dose given at 200 to $400 \mu \mathrm{g}$, with a maximum high dose of $800 \mu \mathrm{g}$ per day. Two RCTs ${ }^{12,13}$ compared budesonide $400 \mu \mathrm{g}$ and fluticasone $400 \mu \mathrm{g}$ on its effect in reduction of polyp size and rhinitis symptoms and showed no significant difference. Comparison of three studies ${ }^{1,10,15}$ showed the following results after fixed effect analysis.

Reduction of polyp size, dose effect: Three studies ${ }^{1,10,15}$ were pooled comparing the $800 \mu \mathrm{g}$ and $400 \mu \mathrm{g}$ dose of intranasal steroids on reduction of polyp size which showed $\mathrm{RR}=1.14(95 \% \mathrm{Cl}$ : $0.78,1.66)$. A test of heterogeneity showed the studies were not comparable $\left(X^{2}=6.12, p=0.01\right)$ and therefore no conclusions could be made.

Reduction of rhinitis symptoms, dose effect: Three studies $1^{1,10,15}$ were combined to show the effect of dose on rhinitis symptoms with use of intranasal steroids for 2 to 4 weeks duration. Two different 
intranasal steroids were represented in the trials, namely budesonide and fluticasone.

There was no significant difference between the $400 \mu \mathrm{g}$ and $800 \mu \mathrm{g}$ dose of intranasal steroids on reduction of rhinitis symptoms ( $R R=0.91$; $95 \% \mathrm{Cl}: 0.77,1.09)$. A test of heterogeneity showed the studies were homogeneous and comparable $\left(X^{2}=1.47, p=0.48\right.$, Figure 6).

\section{DISCUSSION}

The medical treatment of nasal polyps with intranasal corticosteroids has been studied extensively showing good clinical outcomes. Given the large quantity of information on intranasal steroids for nasal polyps, this systematic review sought to quantitatively analyze the effect of intranasal corticosteroids on polyp size and rhinitis symptoms. The review focused on the short-term (2 to 4 weeks) and long-term (4-12 weeks and $>12$ weeks) use of intranasal steroids to address clinician's queries on duration of therapy for optimal results. Since the use of intranasal steroids for nasal polyps in clinical practice has become common, the adverse effects of epistaxis, nasal itchiness and throat irritation were included in this review. The $400 \mu \mathrm{g}$ and $800 \mu \mathrm{g}$ (low versus high) dose of intranasal steroids was also compared to determine if greater benefits obtained with increased dose. A total of 16 RCTs were included in this meta-analysis.

Interpretation of the Benefit of Treatment: The short-term use of intranasal steroids for 2-4 weeks was significant in the reduction of polyp size, with three times the relative benefit compared to placebo. The anti-inflammatory effect of intranasal steroids immediately showed a response within the first four weeks of treatment for nasal polyps of all sizes.

The studies on long-term use of 4-12 weeks were not conclusive with regards effect on polyp size when analyzed together because they were not comparable following a test of heterogeneity. When sensitivity analysis was done, reduction of polyp size was more visible after four weeks of treatment in big compared to small polyps. Therefore, reduction of nasal polyp size may be achieved with short-term intranasal steroids in small polyps and long-term use for big polyps.

Overall rhinitis symptomatology is a summary of the different symptoms of nasal obstruction, rhinorrhea and sneezing. Overall rhinitis symptoms were significantly reduced by one and half times compared to placebo in all sizes of polyps only with intranasal steroids given over a long-term duration of 4-12 weeks and $>12$ weeks.

The summary effect on overall rhinitis symptoms for short-term use of 2-4 weeks was not conclusive because of heterogeneity. With sensitivity analysis, the studies with the following characteristics were comparable: small polyp size, date of publication after 1990, non-drug sponsored studies, and sample size $<50$. With small polyps, summary effect drastically changed from 2.5 - 4 times benefit. However, for the rest of the factors, summary effect changed from 2.5 -1.5 times. The reduction in overall rhinitis symptoms was more apparent for small polyps compared to big polyps with 2-4 weeks use of intranasal steroids. Positive results for articles published after 1990 may be related to increased awareness of the advantages of intranasal steroids by researchers and clinicians. With these premises, the sensitivity analysis done was just a theoretical exercise to find out with which factors the studies would be comparable. Still the final summary effect was that the reduction of overall rhinitis symptomatology was seen only for long-term intranasal steroid use over 4-12 weeks and $>12$ weeks, and not for short-term use of $2-4$ weeks.

The PNIF would have been a good objective measure of nasal obstruction. However, the studies could not be pooled for analysis because the standard deviations or variances were not available, leading to the decision to exclude this measure.

The summary effect showed that there was no significant difference in the reduction of rhinitis symptoms between $400 \mu \mathrm{g}$ and $800 \mu \mathrm{g}$ of intranasal steroids with results showing that effects were not doserelated. Reductions in rhinitis symptoms in many patients who use $<400 \mu \mathrm{g}$ intranasal steroids suggest that dose may not really matter. Because of heterogeneity, the comparative effects of 400 and $800 \mu \mathrm{g}$ doses on polyp size was also not conclusive.

Adverse Effects of Treatment: Significantly, of the three adverse effects included in this review, only throat irritation was most frequently seen with the use of intranasal steroids as compared to use of placebo. Compared to placebo, patients have twice the chance of more symptoms of throat irritation, which may mimic the postnasal drip experienced by patients with rhinitis. In clinical practice, this may be interpreted as postnasal drip or any after-taste from application of the intranasal steroids. Two studies that reported nasal itchiness showed that there was no difference between the treatment and the placebo groups.

Seven studies reported epistaxis but could not be pooled or analyzed because they were positive for heterogeneity. With sensitivity analysis for epistaxis, the studies with the following characteristics were comparable: 1) publications on or earlier than 1990, non-drug company-sponsored studies, small sample size $(<50)$ and the presence of small polyps. When all of these factors were considered, the studies became homogeneous but there was no significant difference in the frequency of epistaxis between the intranasal steroid and the placebo group. This meta-analysis showed that epistaxis may occur with the use of intranasal steroids or any non-medicated application to the nasal mucosa.

In conclusion, this meta-analysis of 16 randomized clinical trials on intranasal steroids for nasal polyps in adults showed that:

- There is a significant reduction of polyp size with short-term treatment of intranasal steroids at 2 to 4 weeks ( $R R=3.0,95 \% \mathrm{Cl}: 2.39$, 3.77).

- There is a significant reduction of overall rhinitis symptoms with long-term treatment of intranasal steroids at 4 to 12 weeks ( $R R=1.64$, $95 \% \mathrm{Cl}: 1.25,2.14)$ and at more than 12 weeks ( $R R=1.41,95 \% \mathrm{Cl}: 1.05$, 1.91).

- In two studies, throat irritation was reported more frequently with intranasal steroid use than with placebo $(\mathrm{RR}=2.06,95 \% \mathrm{Cl}: 1.31,3.25)$

- There was no significant difference in nasal itchiness between both the intranasal steroid and placebo groups ( $\mathrm{RR}=1.33,95 \% \mathrm{Cl}: 0.72,2.45)$.

- There was no significant difference in the use of $400 \mu \mathrm{g}$ and $800 \mu \mathrm{g}$ intranasal steroids in the reduction of overall rhinitis symptoms (RR = $0.91,95 \% \mathrm{Cl}: 0.77,1.09)$. 
- The PNIF would have been a good objective way to measure nasal obstruction. However, the studies could not be pooled for analysis because of missing information either on the variance, the test-statistic or the $p$-value.

\section{Recommendations}

Implications for Practice: This meta-analysis documented quantitative evidence to recommend intranasal steroid therapy use for nasal polyps in adults for a short duration of 2-4 weeks to reduce polyp size and 4-12 weeks and $>12$ weeks to reduce rhinitis symptoms. Adverse effects are minimal and should not inhibit the clinician from prescribing intranasal steroids when clinically warranted.

\section{ACKNOWLEDGEMENT:}

I would like to thank the two reviewers who helped with study selection and data extraction: Teresa Paz B. Grecia - Pascual, LLB, MD (Medical Specialist 1, Veterans Memorial Medical Center; Assistant Professor, De La Salle Health Science Institute) and Joselito M. Acuin, MD, MSc (Past Chairman Dept of ENT, De La Salle Health Science Institute)

\section{REFERENCES}

1. Lildholdt T, Rundcrantz H, Lindqvist $\mathrm{N}$. Efficacy of topical corticosteroid powder for nasal polyps: a double blind placebo-controlled study of budesonide. Clin Otolaryngol 1995;20:26-30.

2. Chalmers 1983. Chalmers TC, Celano P, Sacks HS, Smith H. Bias in treatment assignment in controlled clinical trials. NEngl J Med 1983; 309:1358-61.

3. Settipane G, Lund V, Bernstein J, Tos M. Nasal Polyps: Epidemiology, Pathogenesis and Treatment OceanSide Publications Inc., Providence Rhode Island 1997.

4. Wigand M., Hosemann W. Microsurgical treatment of recurrent polyposis. Rhinology Suppl.,8,2530,1989.

5. Philippine Cardiovascular Research Group (Philippine Cardiovascular Group Quality Assessment Tool, Department of Medicine, Philippine General Hospital.

6. Johnasen LV, Illum P, Kristensen S, Winther L, Petersen SV, Synnerstad B. The effect of budesonide( Rhinocort) in the treatment of small and mediun sized nasal polyps. Clin Otolaryngol 1993;18:524-7.

7. Cooper H, Hedges L. The Handbook of Research Synthesis. New York :Russell Sage Foundation 1994, 384-98.

8. Emerson 1990. Emerson JD, Burdick E, Hoaglin DC, Mosteller F, Chalmers TC. An empirical study of the possible relation of treatment differences to quality scores in controlled randomized clinical trials. Controlled Clin Trials 1990; 1:339-52.

9. Mackay IS. Topical medical management of allergic conditions of the nose. Par 2: Intranasal steroids. In: Mackay IS ed. Rhinitis: Mechanism and Management. London: Royal Society of Medicine Services Ltd, 1989: 183-98.

10. Pentilla M, Poulsen $P$, Hollingworth $K$, Holmstrom M. Dose-related efficacy and tolerability of fluticasone propionate nasal drops 400 microg once daily and twice daily in the treatment of bilateral nasal polyposis: a placebo-controlled randomized study in adult patients. Clin Exp Allergy 2000 Jan;30(1):94-102.

11. Dingsor G, Kramer J, Olsholt R, Soderstrom T. Flunisolide nasal spray $0.025 \%$ in the prophylactic treatment ;of nasal polyposis after polypectomy: A randomized double blind parallel, placebocontrolled study. Rhinology 1985;23:49-58.

12. Holmberg K, Juliusson S, Bladder B, Smith DL. Fluticasone propionate aqueous nasal spray in the treatment of nasal polyposis. Ann of Allergy Asthma \& Immuno.1997Mar;78(3):270-6.
Recommendations for Research: Documentation of new and unusual adverse effects of long-term intranasal steroid administration such as fungal infection is recommended. The benefit of intranasal steroids in children should be looked into to check the reliability of reports of increased recurrence rate of polyps after surgical removal in children.

Following conclusion of this meta-analysis, the searches were rerun for primary studies up to October 2007 using the same strategies, yielding four studies that have since been published. $24,25,26,27$ These four studies should be subjected to the same criteria for inclusion in this review in order to compare their findings with ours.
13. Lund V, Flood J, Sykes A, Ricards D. Effect of Fluticasone in Severe Polyposis. Arch Otol Head and Neck Surg 1998;124:513-8.

14. Tos M. Svendstrups F, Arndal H. Efficacy of an Aqueous and a Powder Formulation of Nasal Budesonide Compared in Patients with Nasal Polyps. Am J Rhinology Suppl 1998;12.

15. Lildholdt T, Rundcrantz H, Bende M, Larsen K. Glucocorticoid Treatment of Nasal Polyps. The Use of Topical Budesonide Poweder, Intramuscular Betamethasone and Surgical Treatment. Arch Head and Neck Surg;1997(123):595-8.

16. Karlsson G, Rundcrantz H. A randomized trial of intranasal beclomethasone dipropionate after polypectomy. Rhinology 1982; 20:144-8.

17. Mygind N, Pedersen CB, Prytz S, Sorensen H. Treatment of Nasal Polyps with intranasal beclomethasone dipropionate aerosol. Clin Allergy 1975;5.

18. Virolainen R, Puhakka Virolainen. The Effect of Intranasal beclomethasone dipropioante on the recurrence of nasal polyposis. Rhinology 1980;18:9-18.

19. Chalton R, Mackay I, Wilson R, Cole P. Double blind, placebo controlled trial of bethamethasone nasal drops for nasal polyposis. Br Med J (Clin Res Ed) 1985;291(6498):788.

20. Holopainen E, Grahne B, Mamberg H, Makinen J, Lindqvist N. Budesonide in the treatment of nasal polyposis. Eur L Respir Dis 1982;63(122):221-8.

21. Toft A, Wihl JA, Toxman J, Mygind N. Double blind comparison between beclomethasone dipropionate as aerosol and as powder in patients with nasal polyposis. Clin Allergy 1982;12:391401.

22. Ruhno J, Anderson B, Denburg J et al. A double blind comparison of intranasal budesonide with placebo for nasal polyposis. J Allergy Clin Immunol 1990;86:946-5

23. Jankowski R, Schrewelius C, Bonfils P, Saban Y, Gilain L, Prades JM, Strunski V. Efficacy and tolerability of budesonide aqueous nasal spray treatment in patients with nasal polpys. Arch Otolaryngol Head Neck Surg 2001Apr;127(4):447-52.

24. Aukema AA, Mulder PG, Fokkens WJ. Treatment of nasal polyposis and chronic rhinosinusitis with fluticasone propionate nasal drops reduces need for sinus surgery. J Allergy Clin Immunol. 2005 May; 115(5):1017-23.

25. Small CB, Hernandez J, Reyes A, Schenkel E, Damiano A, Stryszak P, Staudinger H, Danzig M. Efficacy and safety of mometasone furoate nasal spray in nasal polyposis. 3: J Allergy Clin Immunol. 2005 Dec;116(6):1275-81.

26. Stjärner $P$, Mösges $R$, Jorissen $M$, Passàli $D$, Bellusi $L$, Staudiner $H$, Danzig M. A randomized controlled trial of mometasone furoate nasal spray for the treatment of nasal polyposis. Arch Otolaryngol Head Neck Surg. 2006 Feb; 132(2): 179-85.

27. Stjärne P, Blomgren K, Cayé-Thomasen P, Salo S, Søderstrøm T. The efficacy and safety of oncedaily mometasone furoate nasal spray in nasal polyposis: a randomized, double-blind, placebocontrolled study. Acta Otolaryngol. 2006 Jun;126(6):606-12. 